\title{
Phytochemical Investigation of Antimicrobial and Antioxidant Activity Leaves Extracts of Corchorus olitorius
}

\author{
Rehab Mobark Osman Mohammed \\ Department of Pharmacognosy, Faculty of Pharmacy, University of Al-Neelain, Khartoum, Sudan \\ Email: rehabchem@hotmail.com
}

Received 18 December 2015; accepted 1 January 2016; published 5 January 2016

Copyright (C) 2016 by author and OALib.

This work is licensed under the Creative Commons Attribution International License (CC BY). http://creativecommons.org/licenses/by/4.0/

(c) (i) Open Access

\section{Abstract}

The leaves extracts of Corchorus olitorius, the family Malvaceae, are commonly called khudra, the plant extensively used in Sudanese traditional medicine. The Sudanese varieties are one of the best in the market, which prompted investigation of leaves extracts. Some chemical analyses of the leaves have been done such as determination of ash content and trace elements ( $\mathrm{Ca}, \mathrm{Fe}, \mathrm{Mg}$, and $\mathrm{Na}$ ) by atomic absorption spectrometry. The $96 \%$ ethanolic, Ethyl acetate and chloroform extracts exhibited significant antimicrobial activity and highlighted the biological monitoring of activity in order to isolate the active metabolites from the ethanolic extract of the leaves. The presence of sterols and triterpenes, carotenoids, coumarins, alkaloids, saponins, tannins, flavonoid and carbohydrates was confirmed by phytochemical screening of the diethyl ether, methanolic and aqueous extracts of the leaves. The extracts were screened in different solvent systems by thin layer chromatography. The methanolic, Ethyl acetate extract exhibited significant antioxidant activity. From the above-mentioned extract we prepare cream and ointment as antibacterial and antifungal dosage forms.

\section{Keywords}

Phytochemical Screening, Extract, Corchorus olitorius Leaves, Antimicrobial Activity, Minerals Content

Subject Areas: Pharmacology

\section{Introduction}

The Family Malvaceae is commonly called the khudra tree rich in volatile oils and terpnoids, glycosides and alkaloids, many of them with remarkable antimicrobial activities [1]. The leaves of comprising species showed 
wide range of biological activities, especially the leaves extracts of Corchorus olitorius.

The leaves were extracted with 96\% ethanol, chloroform and methanol; the extracts were tested against Gram positive and Gram negative bacteria; the extracts exhibited significant activity; the methanolic extract gave the highest activity and was selected for further phytochemical investigations.

The results of phytochemical screening and antibacterial assessment of activity along with chemical analysis of the leaves are reported in the present work.

\section{Materials and Methods}

The leaves extracts of Corchorus olitorius were collected from fruits purchased from the local market and were identified at the medicinal and Aromatic plants Institute, the National Centre for Research, Khartoum, Sudan.

The following microorganisms were used for Assessment of antimicrobial activity: which screened against Gram positive (Enterrococcus fecealis and Bacillus subtilis) and Gram negative bacteria (Escherichia coli, Proteus vulgaris, Klebsiella spp., Serratia marcescens).

Media: Nutrient agar, Muller Hinton, Nutrient borth.

\subsection{Preparation of Extracts}

The powdered leaves ( $25 \mathrm{~g}$ ) were extracted separately in a soxhlet apparatus and after removal of solvents. The percentage yields were determined the extracts were used for phytochemical screening and antimicrobial activity assessment and chromatographic analysis for isolation and identification of active constituents [2].

\subsection{Assessment of Antimicrobial Activity}

Antibacterial activity was studied by agar-diffusion method. Each of the inocula of the test organism (1 ml) was poured in to sterile petri-dish. Amedium (about $45 \mathrm{c}$ ) was poured in to each of the petri dishes ( $20 \mathrm{ml}$ ). The medium was left to stand to allow it to set. Coups were bored on the media with the aid of a sterile cork borer of 10 $\mathrm{mm}$ diameter and removal of the agar disc. The cups were marked, and then different concentrations of the plant extracts were pipetted in to the cups using sterile syringes. Plates were then incubated at $37 \mathrm{c}$ for $24 \mathrm{hrs}$. The sensitivities of the test organisms to the plant extracts were indicated by clear zones of growth inhibition around the cups containing the plant extracts and the diameter of the clear zone was taken as an index of the degree of sensitivity [3] and [4].

\subsection{Phytochemical Screening}

The powdered plants were screened for the presence of alkaloids, carotenoids, coumarins, alkaloids, saponins, tannins carbohydrate and phlobannins according to the methods described by Sofowora [1].

\subsection{Chromatographic Analysis}

The extracts were screened in different solvent systems by thin layer chromatography [5].

\subsection{Antioxidant DPPH Radical Scavenging Assay}

The DPPH radical scavenging was determined according to the method of Shimada et al. [6] with some modification. In 96-wells plate, the test samples were allowed to react with 2.2Di (4-tert-octylphenyl)-1-picryl-hydrazyl stable free radical (DPPH) for half an hour at $37^{\circ} \mathrm{C}$. The concentration of DPPH was kept as (300 $\left.\mu \mathrm{M}\right)$. The test samples were dissolved in DMSO while DPPH was prepared in ethanol. After incubation, decrease in absorbance was measured at $517 \mathrm{~nm}$ using multiplate reader spectrophotometer. Percentage radical scavenging activity by samples was determined in comparison with a DMSO treated control group. All tests and analysis were run in triplicate.

\subsection{Iron Chelating Activity Assay}

The iron chelating ability was determined according to the modified method of Dinis et al. [7]. The $\mathrm{Fe}^{2+}$ were monitored by measuring the formation of ferrous ion-ferrozine complex. The experiment was carried out in 96 microtiter plate. The plant extracts was mixed with $\mathrm{FeSO}_{4}$. The reaction was initiated by adding $5 \mathrm{mM}$ ferrozine. 
The mixture was shaken and left at room temperature for 10 min. the absorbance was measured at $562 \mathrm{~nm}$. EDTA was used as standard, and DMSO as control. All tests and analysis were run in triplicate.

\subsection{Creams}

Creams are viscous emulsions of semi-solid consistency, which may be of an oil-in-water type (aqueous creams) or water-in-oil type (oily creams) [8].

\section{Preparation of Creams}

The apparatus used in the preparation of creams and the final containers should, before use, be thoroughly cleansed, then rinsed with purified water which has freshly boiled and cooled, and finally dried. Freshly boiled and cooled purified water should be used in the preparation of all creams, and hygienic precautions should be taken throughout the preparation and subsequent filling into containers. Dissolve the extract of plant in a portion of the alcohol, add Emulsifying Wax; Olive oil and Vaseline [8].

\subsection{Minerals Content}

Minerals content were determined by atomic absorption spectrometry (Agilent, Perkin Elmer AAS Device Model GBC 932, U.S.A. 1996) [9].

\section{Results and Discussion}

The powdered leaves of Corchorus olitorius were extracted with 96\% ethanol, chloroform and methanol. Table 1 showed the antimicrobial activity of ethanolic, Ethyl acetate and chloroform extracts, which screened against Gram positive (Enterrococcus fecealis and Bacillus subtilis) and Gram negative bacteria (Escherichia coli, Proteus vulgaris, Klebsiella spp., Serratia marcescens).

Phytochemical screening of extracts revealed the presence of sterols and triterpenes, carotenoids, alkoloids, tannins, saponins, coumarins and carbohydrates.

The leaves of Corchorus olitorius methanolic, Ethyl acetate extract showed better antioxidant activity when compare to standard EDTA by DPPH scavenging assay method. \%RSA were $0.01 \pm 23$ and $0.01 \pm 17$ for the methanolic, Ethyl acetate extract and standard EDTA $0.00 \pm 92$ respectively but the method of Iron chelating activity assay showed the extract inactive as in Table 2.

In Plate 1 TLC of Ethanolic extract of Corchorus olitorius Stationary phase Silica gel 60 precoated plates, thikeness $20 \mathrm{~mm}$ the Mobile phase by used N-butanol:glacial acidic acid:water (5:4:1) Detection by UV-light (366 nm) which exhibited the presence of chemical compounds.

From the above-mentioned extract we prepare cream and ointment as antibacterial and antifungal dosage forms.

Some chemical analyses of the leaves have been done such as determination of ash content (1.1\%) minerals and trace elements (Ca; Fe; Mg; and $\mathrm{Na}$ ) Table 3.

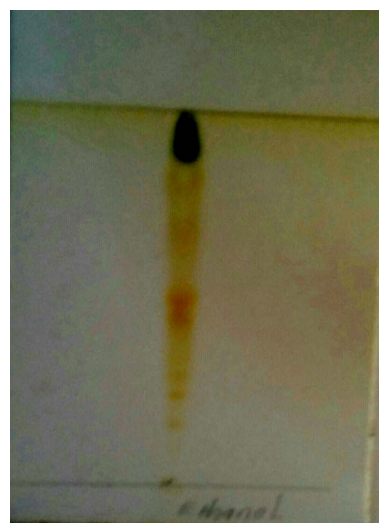

Plate 1. TLC of ethanolic extract of Corchorus olitorius stationary phase = silica gel 60 precoated plates, thikeness $0.20 \mathrm{~mm}$. Mobile phase: N-butanol: glacial acidic acid:water (5:4:1). Detection: UV-light (366 nm). 
Table 1. Results of antimicrobial activity screening of the $96 \%$ elhanolic, chloroform and Ethyl acetate extracts of Corchorus olitorius leaves.

\begin{tabular}{|c|c|c|c|c|}
\hline \multirow{2}{*}{ Organisms } & \multirow{2}{*}{$\begin{array}{c}\text { Concentration } \\
(\mathrm{mg} / \mathrm{ml})\end{array}$} & \multicolumn{3}{|c|}{ Inhibition zone $(\mathrm{mm})$ of extract } \\
\hline & & $96 \%$ ethanol & Chloroform & Ethyl acetate \\
\hline \multirow{4}{*}{ Bacillus subtilis } & 1.00 & 18 & 14 & 20 \\
\hline & 0.75 & 18 & 14 & 18 \\
\hline & 0.50 & 20 & 14 & 18 \\
\hline & 0.25 & 20 & 15 & 17 \\
\hline \multirow{4}{*}{ Klebsiella spp. } & 1.00 & 11 & 14 & 11 \\
\hline & 0.75 & 11 & 14 & 12 \\
\hline & 0.50 & 14 & 14 & 15 \\
\hline & 0.25 & 14 & 14 & 16 \\
\hline \multirow{4}{*}{ Escherichia coli } & 1.00 & 14 & 14 & 13 \\
\hline & 0.75 & 15 & 14 & 14 \\
\hline & 0.50 & 20 & 16 & 12 \\
\hline & 0.25 & 13 & 16 & 15 \\
\hline \multirow{4}{*}{ Proteus vulgaris } & 1.00 & 20 & 11 & 14 \\
\hline & 0.75 & 21 & 15 & 16 \\
\hline & 0.50 & 22 & 12 & 18 \\
\hline & 0.25 & 22 & 14 & 20 \\
\hline \multirow{4}{*}{ Serratia marcescens } & 1.00 & 14 & 18 & 15 \\
\hline & 0.75 & 17 & 17 & 15 \\
\hline & 0.50 & 20 & 17 & 18 \\
\hline & 0.25 & 20 & 18 & 20 \\
\hline \multirow{4}{*}{ Enterrococcus fecealis } & 1.00 & 13 & 12 & 12 \\
\hline & 0.75 & 14 & 14 & 13 \\
\hline & 0.50 & 15 & 16 & 16 \\
\hline & 0.25 & 15 & 16 & 16 \\
\hline
\end{tabular}

Table 2. The methanol, Ethyl acetate extract exhibited significant antioxidant activity of Corchorus olitorius leaves extracts.

\begin{tabular}{cccc}
\hline No. & Sample cod & \%RSA \pm SD (DPPH) & \%Iron chelating \pm SD \\
\hline 1 & Ethylacetate extract & $\mathbf{0 . 0 1} \pm \mathbf{2 3}$ & In active \\
2 & Methanol extract & $\mathbf{0 . 0 1} \pm \mathbf{1 7}$ & In active \\
3 & PG/EDTA & $\mathbf{0 . 0 0} \pm \mathbf{9 2}$ & $\mathbf{0 . 7} \pm \mathbf{9 5}$ \\
\hline
\end{tabular}

Table 3. Chemical analysis of Corchorus olitorius leaves.

\begin{tabular}{lc}
\multicolumn{1}{c}{ Item } & Content (ppm) \\
\hline 1) Calcium (Ca) & 486.8 \\
2) Iron (Fe) & 29.89 \\
3) Magnesium (Mg) & 32.77 \\
4) Manganese (Mn) & 32.77 \\
\hline
\end{tabular}




\section{Conclusion}

Recent studies report important uses of leaves extracts of Corchorus olitorius leaves in complementary medicine and we recommend more studies on the leaves varieties in the market.

\section{References}

[1] Elghazali, G.E., Elsadig, W., Elsubki, H. and Kalafalla, M. (2003) Medicina Plants of the Sudan. Part V. Medicinal Plants of Ingassana Area. National Centre for Researches, Medicinal and Aromatic Plants, Researches Institute, Khartoum.

[2] Sofowora, A. (1993) Phytochemical Screening of Medicinal Plants and Traditional Medicine in Africa Edition. Spectrum Books Ltd., Nigeria, 150-156.

[3] Kavangh, F. (1972) Analytical Microbiology. In: Kavangh, Ed., Academic Press, New York and London, 1-11.

[4] Atlas, R.M. (1989) Basic and Practical Microbiology. Macmillan Publishing Company, USA.

[5] Stock, R. and Rice, C.B.F. (1967) Rice of Chromatographic Methods. 3rd Edition, Science Paper Backs, London.

[6] Shimada, K., Fujikawa, K., Yahara, K. and Nakamura, T. (1920) Antioxidative Properties of Xanthan on the Antioxidation of Soybean Oil in Cyclodextrin Emulsion. Journal of Agricultural and Food Chemistry, 40, 409-458.

[7] Dinis, T.C.P., Madeira, V.M.C. and Almeida, L.M. (1994) Action of Phenolic Derivates (Acetoaminophen, Salycilate, and 5-Aminosalycilate) as Inhibitors of Membrane Lipid Peroxidation and as Peroxyl Radical Scavengers. Archives of Biochemistry and Biophysics, 315, 161-169. http://dx.doi.org/10.1006/abbi.1994.1485

[8] Ansel, H.C., Allen Jr., L.V. and Popovich, N.G. (2009) Pharmaceutical Dosage from and Drug Delivery Systems. 9th Edition.

[9] AOAC (1989) Official Methods of Analysis of the Association of Official Analytical Chemistry. 4th Edition, Washington DC. 